\title{
Diets of impala from Kruger National Park: evidence from stable carbon isotopes
}

\author{
M. Sponheimer, C.C. Grant, D.J. De Ruiter, J.A Lee-Thorp, D.M. Codron and J. Codron
}

\begin{abstract}
Sponheimer, M., C.C. Grant, D.J. de Ruiter, J.A. Lee-Thorp, D.M. Codron and J. Codron. 2003. Diets of impala from Kruger National Park: evidence from stable carbon isotopes. Koedoe 46(1): 101-106. Pretoria. ISSN 0075-6458.

Impala are known to exhibit dietary flexibility, relying primarily on browse in some areas and graze in others. In this study we use stable isotope analysis of faeces and hair to examine the diets of impala in Kruger National Park. As expected, the data show that impala are mixed-feeders and highly distinct from grazing buffalo and browsing kudu. Moreover, impala, buffalo, and kudu faeces contain $2.1 \%, 1.4 \%$, and $2.9 \%$ nitrogen respectively, suggesting that impala diets are of intermediate quality. There are also marked differences between impala populations in the northern and southern regions of the park. The northern impala graze less than their southern counterparts. This difference probably reflects decreased availability of herbaceous forage in the mopane-dominated north. Males and females also have different diets, with males grazing more than females.
\end{abstract}

Key words: impala, carbon isotopes, faeces, hair, diet.

Sponheimer, M., Department of Archaeology, University of Cape Town, Private Bag, Rondebosch, 7700, RSA $(\square$ Current address: Department of Biology, University of Utah, Salt Lake City, Utah, 84112, USA ); C.C. Grant, School of Animal Plant and Environmental Sciences, University of the Witwatersrand, Private Bag 3, Johannesburg, 2050, RSA; D.J. de Ruiter, Palaeoanthropology Unit for Research and Exploration, University of the Witwatersrand, Private Bag 3, Johannesburg, 2050, RSA; J.A. LeeThorp, D.M. Codron and J. Codron, Department of Archaeology, University of Cape Town, Private Bag, Rondebosch, 7700, Republic of South Africa.

\section{Introduction}

Impala (Aepyceros melampus) are known to exhibit great dietary flexibility. They can make large changes in the percentages of browse and graze consumed seasonally (Monro 1980; Dunham 1982; Smithers 1983; Meissner et al. 1996; Wronski 2002). One study suggested that grasses make up $90 \%$ of impala diets during the rainy season, but only $33 \%$ during the dry season (Meissner $e t$ al. 1996). Impala diets are also believed to differ markedly between localities reflecting changes in local vegetation. For instance, it has been reported that some Tanzanian impala populations eat over $90 \%$ grass (Lamprey 1963), whereas some Zimbabwean populations have diets dominated by browse (Smithers 1983). Here, we investigate the diets of impala from Kruger National Park, South Africa, using stable carbon isotope analysis of faeces and hair. Stable carbon isotopes of hair or faeces have been used to investigate the diets of wildlife (Tieszen \& Imbaba 1980; Van der Merwe et al. 1988; Witt \& Beeton 1997; Wit et al. 1998; Schoeninger et al. 1999), but such studies are few in number. Furthermore, these materials have never been analysed in tandem.

Stable carbon isotope analysis is particularly useful for determining the percentages of browse and graze in the diets of African herbivores (Vogel 1978; Ambrose \& DeNiro 1986). Grasses (graze) in tropical environments use the $\mathrm{C}_{4}$ photosynthetic pathway, while trees, shrubs, and forbs (browse) use the $\mathrm{C}_{3}$ pathway. This results in these food 
types having highly divergent, non-overlapping ratios of ${ }^{13} \mathrm{C} /{ }^{12} \mathrm{C}$ (Smith \& Epstein 1971). Because the carbon from these food sources is incorporated into faeces and hair in well-understood ways (DeNiro \& Epstein 1978; Jones et al. 1981; Cerling \& Harris 1999; O’Connell \& Hedges 1999), we can then use the ${ }^{13} \mathrm{C} /{ }^{12} \mathrm{C}$ ratios of these materials to determine the percentages of graze and browse in an animal's diet.

\section{Methods}

The Kruger National Park is broadly divided into granite-derived soils in the west and basalt-derived soils in the east. The rainfall decreases from south to north and to a lesser extent from west to east (Joubert 1986). Tail hair samples were obtained from darted animals in December, 2001 and faeces were collected in June, 2002. Our collections included animals from the northern and southern regions of the park, to see if the different rainfall regimes led to divergent trophic behavior. In order to provide a comparative baseline, we also gathered tail hair and faeces samples from the grazing cape buffalo (Syncerus caffer) and browsing kudu (Tragelaphus strepsiceros). The darted animals were from healthy populations that were undergoing routine veterinary study by Kruger
National Park staff. Thus, our sampling strategy was perforce opportunistic.

About $6 \mathrm{~cm}$ of tail hair was homogenised so that analysis would provide a long-term dietary average. Hair grows at the rate of about $1 \mathrm{~cm}$ per month (Saitoh et al. 1969), so the samples we analysed represented about 6 months' growth. Faecal samples were dried, homogenised and ground. Hair and faecal samples were combusted in an automated CarloErba device (Carlo-Erba, Milan) and stable carbon isotopes were analysed using a flow-through inlet system on a continuous flow isotope ratio mass spectrometer (Finnigan, Bremen). This provided us with the ${ }^{13} \mathrm{C} /{ }^{12} \mathrm{C}$ ratios and percentage nitrogen of each sample. The ${ }^{13} \mathrm{C} /{ }^{12} \mathrm{C}$ ratios are expressed here as $\delta$ values in parts per thousand (\%) relative to the PDB standard. The standard deviation for replicate measurements of a yeast standard was $<0.1 \%$. Data from grazing buffalo and browsing kudu are included to provide a comparative baseline. We used oneway analysis of variance to look for species, region, and sex differences.

The $\delta^{13} \mathrm{C}$ values were converted to $\% \mathrm{C}_{4}$ consumed using $-12.5 \%$ and $-27.0 \%$ as pure grazing and browsing dietary endpoints (Vogel et al. 1978), and assuming isotopic fractionations of $-0.9 \%$ and +3.0 for faeces and hair respectively (Jones et al. 1981; Cerling \& Harris 1999; Sponheimer pers. obs.). For example, an animal with hair $\delta^{13} \mathrm{C}$ of $-24.0 \%$ would have a dietary $\delta^{13} \mathrm{C}$ of $-27.0 \%$, and thus be

Table 1

Sample size, $\delta^{13} C$ and $\% C_{4}$ grass consumed for all groups in this study. Percent $\mathrm{C}_{4}$ grass consumption was determined assuming fractionations of $-0.9 \%$ and $+3.0 \%$ for faeces and hair respectively (e.g., Jones et al., 1981; Cerling \& Harris 1999). Percent nitrogen is also included for faeces

\begin{tabular}{lcccc}
\hline Species & $\mathrm{N}$ & $\delta^{13} \mathrm{C}$ & $\% \mathrm{~N}$ & $\% \mathrm{C}_{4}$ \\
\hline Faeces & & & & \\
Impala Combined & 39 & $-20.5 \pm 2.8$ & $2.1 \pm 0.5$ & $53 \pm 20$ \\
Impala North & 18 & $-22.2 \pm 2.6$ & $2.1 \pm 0.7$ & $41 \pm 19$ \\
Impala South & 21 & $-19.2 \pm 2.2$ & $2.1 \pm 0.4$ & $63 \pm 16$ \\
Buffalo & 19 & $-14.7 \pm 0.5$ & $1.4 \pm 0.3$ & $95 \pm 3$ \\
Kudu & 19 & $-26.8 \pm 0.4$ & $2.9 \pm 0.5$ & $8 \pm 3$ \\
Hair & & & & \\
Impala Combined & 36 & $-15.2 \pm 3.4$ & na & $63 \pm 24$ \\
Impala North & 18 & $-17.8 \pm 2.8$ & na & $44 \pm 20$ \\
Impala South & 18 & $-12.6 \pm 1.3$ & na & $82 \pm 10$ \\
Impala Female & 13 & $-16.6 \pm 3.8$ & na & $53 \pm 27$ \\
Impala Male & 22 & $-14.6 \pm 3.0$ & na & $67 \pm 21$ \\
Buffalo & 51 & $-10.2 \pm 0.4$ & na & $98 \pm 2$ \\
Kudu & 19 & $-23.5 \pm 0.5$ & na & $4 \pm 3$ \\
\hline
\end{tabular}


a pure browser. Similarly, faeces with a $\delta^{13} \mathrm{C}$ of $-13.4 \%$ would indicate a pure grazing diet with a $\delta^{13} \mathrm{C}$ of $-12.5 \%$.

\section{Results and Discussion}

Both faeces and hair data show impala to be mixed-feeders and significantly different from buffalo and kudu $(P<0.0001)$ (Table 1; Fig. 1). The faeces data suggest impala have a diet of $53 \%$ $\mathrm{C}_{4}$ vegetation (grass), whereas the hair data suggest a diet of $63 \%$ grass. These results are consistent with previous studies of impala in Kruger National Park and elsewhere (Van Zyl 1965; Hofmann \& Stewart 1973; Monro 1980; Smithers 1983; Van Rooyen 1992; Meissner et al. 1996; Vogel 1978; Wronski 2002). The faecal nitrogen contents of impala, buffalo, and kudu are also significantly different $(P<0.0001)$ (Table 1$)$. Befitting a mixed-feeder, impala faecal nitrogen concentrations are higher than those of buffalo, but lower than those of kudu. These findings are also consistent with a multiple year study of ungulate faecal nitrogen concentrations in Kruger National Park (Grant et al. 2000).

Both faeces and hair data also show strong dietary differences between impala from the northern and southern regions of the park $(P<0.0001)$ (Table 1; Fig. 2), with southern impala grazing more than their northern counterparts. The faeces data suggest a diet of $41 \%$ grass in the north and $63 \%$ grass in the south. Similarly, the hair data suggest a $44 \%$ grass diet in the north and a $82 \%$ grass diet in the south. The difference between the faeces and hair data in the south may reflect the fact that the hair data represent a long-term dietary average, whereas the faeces data largely reflect the season when they were collected (the beginning of the dry season). Nonetheless, both data sets concur that impala have different diets in the mopane-dominated north than they do in the marula-knobthorn and bushwillow

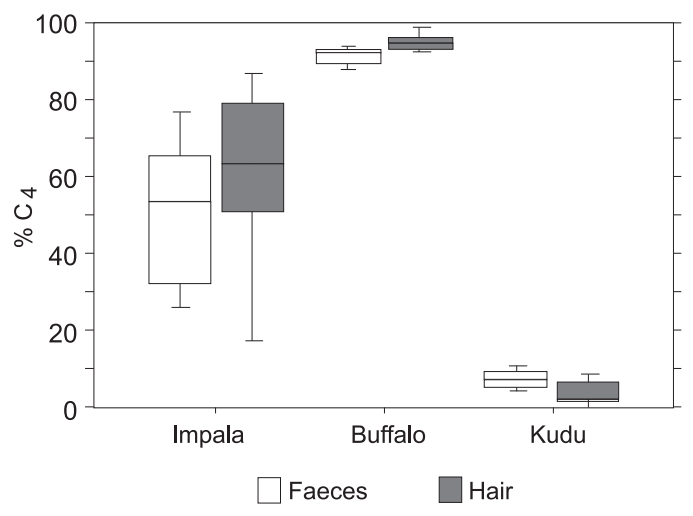

Fig. 1. Boxplot with the median $25-75 \%$ and standard deviation of the dietary percentage of $\mathrm{C}_{4}$ grass consumed by impala, buffalo, and kudu in Kruger National Park. Buffalo eat nearly $100 \% \mathrm{C}_{4}$ grass, kudu eat nearly $100 \%$ browse, and impala clearly eat both. Note the strong similarity between the hair and faeces data.

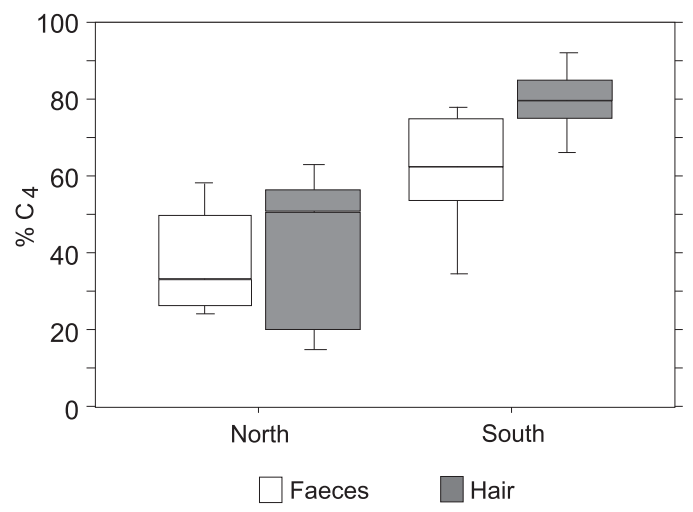

Fig. 2. Boxplot with the median, 25-75\%, and standard deviation of the dietary percentage of $\mathrm{C}_{4}$ grass consumed by impala in the northern and southern regions of Kruger National Park. Note that both hair and faeces data agree that impala graze more in the south.

woodlands of the south (Gertenbach 1983). Intriguingly, there is no difference in the faecal nitrogen concentrations of impala in the north and south of the park (Table 1). This supports the contention of Meissner et al. (1996) that impala optimise their diets for quality forage irrespective of plant composition. 


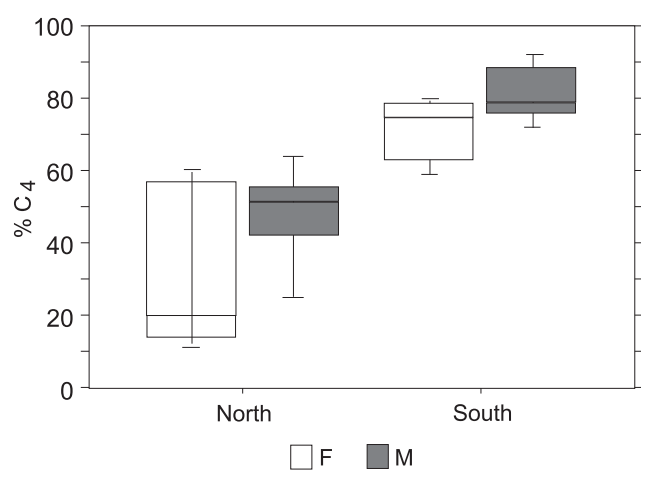

Fig. 3. Boxplot with the median, 25-75\%, and standard deviation of the dietary percentage of $\mathrm{C}_{4}$ grass consumed by male and female impala in the Kruger National Park. Males clearly graze more than females throughout the park, although the difference is only significant in the south.

Because the hair samples were collected from darted individuals, we were also able to look for sex differences in diet. Throughout the park males grazed $14 \%$ more than females (Table 1; Fig. 3); however, this difference was only statistically significant in the southern portion of the park $(P=0.03)$. This provides further evidence for sex based dietary differences as observed by other researchers (Wronski 2002). In future, it might also prove fruitful to explore possible dietary differences associated with disparate social structures. For instance, do males in bachelor herds and those with harems have divergent diets?

\section{Conclusion}

In this study we were able to show regional and sex based dietary differences of impala in Kruger National Park. Further stable isotope analysis should prove a powerful tool for supplementing traditional studies of wildlife diets. Observational studies are very time-consuming, which necessarily limits the number of populations that can be observed. Furthermore, although these studies provide rich detail about the variety of plants consumed and the time spent feeding on each diurnally, they cannot easily quantify the actual amounts of browse and graze consumed both day and night.

In contrast, stable isotope analysis is very fast and can provide precise information on the amount of browse and graze digested. Once samples have been obtained, preparation and analysis of 100 samples can be completed in a single day. Thus, although stable isotope studies cannot be used to identify individual plant species consumed, they are ideal for quickly comparing the percentages of browse and graze consumed by different groups, whether they are intra- or inter-populational.

Stable isotope analysis also has the advantage that it can be used to study extinct populations. The hair of mounted trophies and even fossilised teeth can be used to glean something of the diets of animals long since dead (e.g., Lee-Thorp \& van der Merwe 1987; Macko et al. 1999; Sponheimer et al. 1999). Thus, we can use this tool not only to study the nutritional ecology of modern wildlife, but to study the development of modern dietary adaptations through time.

Moreover, emerging techniques will make it possible to derive even more ecological information from such analyses. For instance, sampling tail hair in small increments $(<1 \mathrm{~cm})$, makes it possible to trace dietary change through time (O'Connell \& Hedges 1999). This should prove particularly useful for documenting seasonal changes in browse and graze consumption. It has also been suggested that nitrogen isotopes in hair can be used as indicators of nutritional stress (Hobson et al. 1993). Given present capabilities and the increasing potential offered by constant technical advances in the field, stable isotope analysis should prove a valuable supplement to traditional studies in mammalian dietary ecology in the future. 


\section{Acknowledgments}

The authors would like to thank the rangers and veterinary staff of Kruger National Park for help in obtaining specimens. We would especially like to thank Charles Trennery, Retha Jansen van Vuuren, Obert Mathebula, Wilson Sondelya, Josiah Baloyi, Shela Patrickson, Adam West and Yasmin Rahman for help in the field, and John Lanham for his invaluable assistance with the mass spectrometer. We also thank two anonymous reviewers for their helpful comments on the manuscript.

\section{References}

Ambrose, S.H. \& M.J. DeNiro. 1986. The isotopic ecology of East African Mammals. Oecologia 69: 395-406.

Cerling. T.E. \& J.M. Harris. 1999. Carbon isotope fractionation between diet and bioapatite in ungulate mammals and implications for ecological and paleoecological studies. Oecologia 120: 347-363.

DeNiro, M.J., \& S. EpsteIN. 1978. Influence of diet on the distribution of carbon isotopes in animals. Geochimica et Cosmochimica Acta 42: 495-506.

DunHAM, K.M. 1982. The foraging behaviour of impala Aepyceros melampus. South African Journal of Wildlife Research 12: 36-40.

Gertenbach, W.P.D. 1983. Landscapes of the Kruger National Park. Koedoe 26: 9-122.

Grant,C.C., M.J.S. Peel, N. Zambatis \& J.B.J. van RYSSEN. 2000. Nitrogen and phosphorus concentration in faeces: an indicator of range quality as a practical adjunct to existing evaluation methods. African Journal of Range and Forage Science 17: 81-92.

Hobson, K.A., R.T. Alisauskas \& R.G. Clark. 1993. Stable nitrogen isotope enrichment in avian tissues due to fasting and nutritional stress: implications for isotopic analysis of diet. Condor 95: 388-394.

HofmanN, R. R. \& D.R.M. Stewart. 1972. Grazer or browser: a classification based on the stomach structure and feeding habits of East African ruminants. Mammalia 36: 226-240.

Jones, R.J., M.M. Ludlow, J.H. Troughton \& C.G. BLUNT. 1981. Changes in natural carbon isotope ratio of the hair from steers fed diets of $\mathrm{C}_{4}, \mathrm{C}_{3}$ and $\mathrm{C}_{4}$ species in sequence. Search 12: 85-87.

JouBERT, S.C.J. 1986. The Kruger National Park - an introduction. Koedoe 29: 1-11.

LAMPREY, H.F. 1963. Ecological separation of the large mammal species in the Tarangire Game Reserve, Tanganyika. East African Wildlife Journal 1: 63-92.
LeE-Thorp, J.A. \& N.J. vAn DER Merwe. 1987. Carbon isotope analysis of fossil bone apatite. South African Journal of Science 83: 712-715.

Macko, S. A., M. H. Engel, V. Andrusevich, G. Lubec, T. C. O'Connell \& R. E. M. Hedges. 1999. Documenting the diet of ancient human populations through stable isotope analysis of hair. Philosophical Transactions of the Royal Society of London B 354: 65-76.

Meissner, H.H., E. Pieterse \& J.H.J. Potgieter. 1996. Seasonal food selection and intake by male impala Aepyceros melampus in two habitats. South African Journal of Wildlife Research 26: 56-63.

Minson, D.J. 1990. Forage in ruminant nutrition. San Diego: Academic Press.

MonRo, R.H. 1980. Observations on the feeding ecology of impala. South African Journal of Zoology 15: 107-110.

O'ConNell, T.C. \& R.E.M. Hedges. 1999. Investigations into the effect of diet on modern human hair isotopic values. American Journal of Physical Anthropology 108: 409-425.

Saitoh, M., M. UzuKa, M. Sakamoto \& T. Kobori. 1969. Rate of hair growth. Pp. 183-201. In: W. Montagna \& R. L. Dobson (eds.). Hair Growth. Oxford: Pergamon Press.

Schoeninger, M.J., J. Moore \& J.M. Sept. 1999. Subsistence strategies of two savanna chimpanzee populations: the stable isotope evidence. American Journal of Primatology 49: 297-314.

SMith, B.N. \& S. EpsteIn. 1971. Two categories of ${ }^{13} \mathrm{C} /{ }^{12} \mathrm{C}$ ratios for higher plants. Plant Physiology 47: 380-384.

SMITHERS, R.H.N. 1983. The mammals of the Southern African subregion. Pretoria: University of Pretoria.

Sponheimer, M., K. ReEd \& J.A. LeE-Thorp. 1999. Combining isotopic and ecomorphological data to refine bovid paleodietary reconstruction: a case study from the Makapansgat Limeworks hominin locality. Journal of Human Evolution 36: 705-718.

Tieszen, L.L. \& S.K. Imbaba. 1980. Photosynthetic systems, carbon isotope discrimination, and herbivore selectivity in Kenya. African Journal of Ecology 18: 237-242.

VAn Der Merwe, N.J., J.A. Lee-Thorp \& R.H.V. BELL. 1988. Carbon isotopes as indicators of elephant diets and African environments. African Journal of Ecology 26: 163-172.

VAN ZYL, J.H.M. 1965. The vegetation of the S.A. Lombard Nature Reserve and its utilization by certain antelope. Zoologica africana 1: 55-71.

VAN RoOYen, A.F. 1992. Diets of impala and nyala in two game reserves in Natal, South Africa. South African Journal of Wildlife Research 22: 98-101. 
Vogel, J. 1978. Isotopic assessment of the dietary habits of ungulates. South African Journal of Science 74: 298-301.

Vogel, J.C., A. Fuls \& R.P. Ellis. 1978. The geographical distribution of kranz grasses in South Africa. South African Journal of Science 74: 209-215.

WitT, G.B. \& R.J. BEETON. 1997. Sheep faeces under shearing sheds: a documentary of vegetation change using stable carbon isotope analysis. Rangeland Journal 19: 109-115.

Witt, G.B., E.J. Moll, R.J. Beeton \& P.J. Murray. 1998. Isotopes, wool and rangeland monitoring: let the sheep do the sampling. Environmental Management 22: 145-152.

WRONSKI, T. 2002. Feeding ecology and foraging behaviour of impala Aepyceros melampus in Lake Mburu National Park, Uganda. African Journal of Ecology 40: 205-211. 